\title{
Avaliação do conhecimento dos estudantes sobre o procedimento de ressuscitação cardiorrespiratória: uma intervenção educativa
}

\author{
Evaluation of students' knowledge about the procedure of cardiorespiratory resuscitation: \\ an educational intervention

\section{Evaluación del conocimiento de los estudiantes sobre el procedimiento de resucitación cardiorrespiratoria: una intervención educativa}

Cynthia Kallás Bachur ${ }^{1,2 *}$, Gérlia Bernardes da Silveira ${ }^{1}$, Eduardo Reinaldo Silva ${ }^{1}$, Amanda Freire de Andrade', Sarah da Silva Candido².

\begin{abstract}
RESUMO
Objetivo: comparar o conhecimento dos estudantes sobre 0 procedimento de ressuscitação cardiorrespiratória, antes e após uma intervenção educativa. Métodos: estudo quase experimental, amostra por conveniência, composta por estudantes de ensino fundamental. Para avaliação do conhecimento teórico sobre a execução dos procedimentos de emergência em parada cardíaca, foi aplicado um questionário de 25 questões, que avaliou os itens: conhecimentos gerais, sequência da ressuscitação, respiração, compressões e uso do desfibrilador externo automático. Para avaliar o conhecimento prático, foi realizada uma simulação realística, com a utilização de um checklist composto por todas as etapas de ressuscitação. Após essas avaliações, os participantes receberam capacitação a partir de uma intervenção educativa. As avaliações teóricas e práticas foram realizadas novamente para fins de comparação. Resultados: Participaram 51 estudantes, com idade média de 13 anos, em ambos os sexos. Na comparação da avaliação teórica, antes e após a intervenção educativa, não houve diferença significante em nenhum dos 5 itens analisados. Já na comparação da avaliação prática observou-se que a intervenção educativa influenciou de forma significativa na média de acertos das etapas dos procedimentos, na maioria dos itens. Conclusão: sugere-se que a intervenção educativa sobre ressuscitação cardiorrespiratória tornou-se eficaz e satisfatória para retenção imediata e tardia de conhecimentos.
\end{abstract}

Palavras-Chave: Educação em saúde, Estudantes, Ressuscitação cardiopulmonar.

\begin{abstract}
Objective: to compare the students' knowledge about the procedure of cardiorespiratory resuscitation, before and after an educational intervention. Methods: almost experimental study, sample for convenience, composed of high school students. To evaluate the theoretical knowledge about the execution of the emergency procedures in cardiac arrest, a questionnaire of 25 questions was applied, which evaluated the items: general knowledge, resuscitation sequence, breathing, compressions and use of the automatic external defibrillator. To evaluate the practical knowledge, a realistic simulation was performed, using a checklist composed of all stages of resuscitation. After these evaluations, participants received training from an educational intervention. Theoretical and practical evaluations were performed again for comparison purposes. Results: 51 students, with a mean age of 13 years, participated in both sexes. In the comparison of the theoretical evaluation, before and after the educational intervention, there was no significant difference in any of the 5 items analyzed. In the comparison of the practical evaluation, it was observed that the educational
\end{abstract}

${ }^{1}$ Universidade de Franca, Franca-SP;

2Universidade de São Paulo, Ribeirão Preto. *E-mail: kabachur@gmail.com

SUBMETIDO EM: 5/2019

ACEITO EM: 6/2019

PUBLICADO EM: 7/2019

REAS/EJCH |Vol. Sup.26 | e911 |DOI: https://doi.org/10.25248/reas.e911.2019 Página 1 de 6 
intervention had a significant influence on the average of correct steps in most of the items. Conclusion: it is suggested that the educational intervention on cardiorespiratory resuscitation has become effective and satisfactory for immediate and late retention of knowledge.

Key words: Health education, Students, Cardiopulmonary resuscitation.

\section{RESUMEN}

Objetivo: comparar el conocimiento de los estudiantes sobre el procedimiento de resucitación cardiorrespiratoria, antes y después de una intervención educativa. Métodos: estudio casi experimental, muestra por conveniencia, compuesta por estudiantes de enseñanza media. Para evaluar el conocimiento teórico sobre la ejecución de los procedimientos de emergencia en paro cardíaco, se aplicó un cuestionario de 25 preguntas, que evaluó los ítems: conocimientos generales, secuencia de la resucitación, respiración, compresiones y uso del desfibrilador externo automático. Para evaluar el conocimiento práctico, se realizó una simulación realista, con la utilización de un checklist compuesto por todas las etapas de resucitación. Después de estas evaluaciones, los participantes recibieron capacitación a partir de una intervención educativa. Las evaluaciones teóricas y prácticas se realizaron de nuevo para fines de comparación. Resultados: Participaron 51 estudiantes, con edad promedio de 13 años, en ambos sexos. En la comparación de la evaluación teórica, antes y después de la intervención educativa, no hubo diferencia significante en ninguno de los 5 ítems analizados. En la comparación de la evaluación práctica se observó que la intervención educativa influenció de forma significativa en la media de aciertos de las etapas de los procedimientos, en la mayoría de los ítems. Conclusión: se sugiere que la intervención educativa sobre resucitación cardiorrespiratoria se ha vuelto eficaz y satisfactoria para la retención inmediata y tardía de conocimientos.

Palabras clave: Educación en salud, estudiantes, Resucitación cardiopulmonar.

\section{INTRODUÇÃO}

A parada cardiorespiratória (PCR) extra-hospitalar é considerada uma das principais causas de morte evitáveis, caso seja realizado um manejo eficiente da vítima. No Brasil o número de mortes anualmente em virtude de tal evento é de cerca de 100.000 pessoas. Em virtude de tal número expressivo, as manobras de suporte básico de vida (SBV) que abordam a ressuscitação cardiopulmonar (RCP) têm sido importante tema de saúde pública, com o intuito de diminuir sequelas e óbitos decorrentes de tais incidentes (GUIMARAES EA, et al., 2016).

Sabe-se que quase a totalidade das PCRs tem o início com ritmos cardíacos desfibriláveis. Sendo assim, caso existam pessoas capazes de reconhecer os sinais de uma PCR e iniciar imediatamente as medidas de RCP com auxílio de um desfibrilador externo automático (DEA), a possibilidade de sucesso é intensificada. Uma vez que, quanto mais rápido for o socorro, maiores são as chances de êxito, logo que cada minuto sem suporte ao doente, perde-se de 7 a $10 \%$ de possibilidade de reanimação. Ademais, a probabilidade de sobrevida nos próximos 30 dias também é aumentada (MORAIS DA, CARVALHO DV, CORREA AR, 2014).

A RCP preza pela manutenção das vias aéreas pérveas, da respiração de suporte e de uma circulação capaz de manter a vida. Os principais motivos conhecidos de não realização de tal técnica por cidadãos que não trabalham na área médica são: não conhecimento dos sinais iniciais de uma PCR; ausência de conhecimentos sobre SBV; receio de contrair alguma doença, ou realizar algo errado. Portanto, a principal explicação para não realização da SBV é falta instrução da população geral sobre a PCR, pois o conhecimento é denominador comum de todas essas justificativas (HASSELQVIST-AX I, et al., 2015).

Quanto mais pessoas souberem sobre PCR extra-hospitalar e medidas a serem executadas em um evento como esse, melhores índices de mortalidade e morbidade pós PCR serão obtidos. Uma boa estratégia para a disseminação desse conhecimento, é a instrução a indivíduos em ambiente escolar, assim como recomenda a American Heart Association (AHA) (TAVARES A, PEDRO N, URBANO J, 2016). 
Não existe um consenso sobre qual melhor idade para iniciar o treinamento de RCP. Sabe-se que crianças com menos de 9 anos de idade apesar de não conseguirem realizar a técnica com maestria, conseguem instruir adultos próximos. Nas crianças com mais de 11 anos são capazes de efetivar tal procedimento. Além do mais, independentemente da idade, quando ensinado tal procedimento, contribui-se para a educação dessas crianças, com o intuito de quese sintam pessoas as quais fazem parte uma sociedade e que possuem deveres morais, assim facilitando futuros aprendizados sobre tal tema abordado (TAVARES, A; PEDRO, N; URBANO, J, 2016).

No Brasil, em 2007, foi criado pelo governo federal um projeto intitulado: Samuzinho. O objetivo de tal medida é a intervenção em escolas, visando a educação de crianças e adolescentes sobre a função do Serviço de Atendimento Móvel de Urgência (SAMU). Assim como, quais medidas devem ser tomadas em situações de urgência e emergência (MOTA LL, 2013).

Frente a estes dados, o objetivo deste estudo foi comparar o conhecimento teórico e prático dos estudantes sobre as etapas do procedimento de RCP, antes e após uma intervenção educativa.

\section{METODOLOGIA}

Trata-se de um estudo de caráter observacional, quase experimental. A amostra por conveniência foi composta por estudantes/adolescentes, matriculados em uma escola de rede privada, cursando o ensino fundamental, em uma cidade no interior do estado de São Paulo, no ano de 2018.

Primeiramente, houve um agendamento prévio com a direção da escola para que esta intervenção não prejudicasse as atividades escolares cotidianas.

Para avaliar o conhecimento teórico, aplicou-se um questionário composto por 25 questões de múltipla escolha, com 4 alternativas, sendo apenas uma correta e que valia 1 ponto, divididos em 5 itens: conhecimento geral sobre gerais, sequência da ressuscitação, respiração, compressões e uso do desfibrilador externo automático.

Para avaliação prática, foi realizado uma simulação de atendimento e o utilizou-se um checklist, com 18 itens que favorecia a aquisição de conhecimento em situações práticas com ambientes reais.

No segundo momento, todos os estudantes participaram de uma intervenção educativa, a partir de aulas expositivas, com duração de duas horas, alternando o conhecimento teórico, com abertura para debates e discussões das lacunas do conhecimento.

Utilizou-se também para a parte prática, bonecos de simulação e o DEA, com o intuito de tornar o ambiente realístico, a partir de um role play.Após 15 dias da intervenção educativa, reaplicou-se os instrumentos, teórico e prático, afim de determinar o conhecimento assimilado e analisar os pontos de erros e acertos. Propôs também que os três estudantes com melhores índices de acertos fossem intitulados como socorristas mirins, assumindo a responsabilidade em repassar os conhecimentos obtidos ao restante da escola, quando solicitados.

Como critério de inclusão foram os estudantes presentes no dia da coleta de dados e excluídos aqueles que não tiveram a autorização dos pais para participação, ou que se que recusaram a participar do projeto. Os dados foram armazenados em um banco de dados no programa Microsoft Excel® e processados pelo programa Statistical Package for the Social Sciences® (SPSS) versão 16.0.

Para as análises das comparações pré e pós intervenção educativa, utilizou-se o teste $T$ Student, considerado o nível de significância $p<0,05$.

Este trabalho foi aprovado pelo Comitê de Ética em Pesquisa, protocolo CAAE №64592817.9.0000.5495 e obedeceu aos princípios éticos e legais da resolução no 466/12.

Todos os participantes assinaram o Termo de Assentimento juntamente com os responsáveis que voluntariamente assinaram o Termo de Consentimento Livre e Esclarecido.

REAS/EJCH |Vol. Sup.26 | e911 |DOI: https://doi.org/10.25248/reas.e911.2019 Página 3 de 6 


\section{RESULTADOS}

Participaram do estudo 51 estudantes regularmente matriculados no ensino fundamental, sendo 26 $(50,98 \%)$ do sexo feminino e $25(49,01 \%)$ do sexo masculino com idade média de $13,50 \pm 0,50$ anos. Na avaliação do conhecimento teórico dos estudantes, não foi possível identificar diferença significativa na quantidade de acertos nos domínios específicos entre a pré e pós intervenção educativa. A Tabela 1 apresenta a comparação da frequência das respostas corretas, entre a pré e pós intervenção, com valores apresentados como média \pm desvio padrão da amostra de todos os estudantes.

Tabela 1 - Comparação da frequência de respostas corretas a partir dos 5 domínios avaliados nos estudantes na avaliação teórica, Franca, 2018, $(n=51)$.

\begin{tabular}{lccc}
\hline Domínios & $\begin{array}{c}\text { Pré intervenção } \\
\text { Média } \pm \text { DP }\end{array}$ & $\begin{array}{c}\text { Pós intervenção } \\
\text { Média } \pm \text { DP }\end{array}$ & Valor $\boldsymbol{p}^{*}$ \\
\hline Conhecimentos gerais & $22,33 \pm 19,65$ & $30,67 \pm 15,04$ & 0,145 \\
Sequência procedimentos & $30,55 \pm 10,91$ & $35,67 \pm 5,22$ & 0,342 \\
Ventilações & $21,50 \pm 4,94$ & $21,50 \pm 17,68$ & 1,000 \\
Compressão & $21,40 \pm 10,52$ & $31,60 \pm 11,50$ & 0,181 \\
Uso do desfibrilador & $19,16 \pm 11,0$ & $28,50 \pm 14,20$ & 0,231 \\
\hline
\end{tabular}

Fonte: Dados de pesquisa 2019. \pm DP: desvio padrão; * ${ }^{*}$ : nível de significância $(p<0,05)$.

Tabela 2 - Distribuição da média e desvio padrão das execuções do procedimento na avaliação prática. Franca, 2018, $(\mathrm{n}=51)$.

\begin{tabular}{|c|c|c|c|}
\hline Etapas do procedimento & $\begin{array}{l}\text { Pré } \\
\text { intervenção } \\
\text { Média } \mathbf{D P}\end{array}$ & $\begin{array}{l}\text { Pós } \\
\text { Intervenção } \\
\text { Média } \pm \text { DP }\end{array}$ & Valor $p^{*}$ \\
\hline $\begin{array}{l}1 \text { - Posicionou-se ao lado da vítima e manteve seus joelhos com certa } \\
\text { distância um do outro }\end{array}$ & $1,66 \pm 0,73$ & $2,29 \pm 0,80$ & $<0,001^{*}$ \\
\hline $\begin{array}{l}2 \text { - Deixou o tórax da vítima desnudo para realização de futuras } \\
\text { compressões }\end{array}$ & $1,0 \pm 0,89$ & $1,76 \pm 1,27$ & $<0,001^{*}$ \\
\hline $\begin{array}{l}3 \text { - Colocou a região hipotênar de uma mão sobre o esterno da vítima e } \\
\text { a outra mão sobre a primeira, entrelaçando-a. }\end{array}$ & $1,52 \pm 1,0$ & $2,37 \pm 0,79$ & $<0,001^{*}$ \\
\hline 4 - Estendeu os braços e os posicionou cerca de $90^{\circ}$ acima da vítima. & $1,39 \pm 0,89$ & $2,37 \pm 0,79$ & $<0,001^{*}$ \\
\hline 5 - Realizou 30 compressões para 2 ventilações. & $1,03 \pm 0,69$ & $1,98 \pm 0,96$ & $<0,001^{*}$ \\
\hline 6 - Comprimiu com profundidade, no mínimo, $5 \mathrm{~cm}$. & $1,41 \pm 0,92$ & $2,17 \pm 0,95$ & $<0,001^{*}$ \\
\hline $\begin{array}{l}7 \text { - Abriu a via aérea com a inclinação da cabeça/elevação do queixo } \\
\text { ou elevação do ângulo da mandíbula. }\end{array}$ & $0,27 \pm 0,49$ & $1,45 \pm 1,23$ & $<0,001^{*}$ \\
\hline $\begin{array}{l}8 \text { - Aplicou a ventilação com fornecimento da quantidade de ar } \\
\text { suficiente para promover elevação do tórax. }\end{array}$ & $0,27 \pm 0,53$ & $1,39 \pm 1,23$ & $<0,001^{*}$ \\
\hline $\begin{array}{l}9 \text { - Permitiu o retorno completo do tórax após cada compressão, sem } \\
\text { retirar o contato das mãos com o mesmo. }\end{array}$ & $1,15 \pm 1,15$ & $2,13 \pm 1,05$ & $<0,001^{*}$ \\
\hline 10 - Ligou o aparelho apertando o botão ON - OFF. & $1,58 \pm 1,29$ & $2,27 \pm 1,11$ & $<0,001^{*}$ \\
\hline $\begin{array}{l}11 \text { - Conectou as pás (eletrodos) no tórax da vítima, observando o } \\
\text { desenho contido nas próprias pás. }\end{array}$ & $1,37 \pm 1,31$ & $1,98 \pm 1,15$ & $0,014^{*}$ \\
\hline 12 - Encaixou o conector das pás (eletrodos) ao aparelho. & $1,56 \pm 1,36$ & $1,80 \pm 1,23$ & 0,359 \\
\hline $\begin{array}{l}13 \text { - Observou se realmente não há ninguém (nem ele mesmo) tocando } \\
\text { a vítima e, então, pressionou o botão indicado pelo aparelho para } \\
\text { aplicar o choque. }\end{array}$ & $1,37 \pm 1,21$ & $2,07 \pm 1,12$ & $0,003^{*}$ \\
\hline $\begin{array}{l}14 \text { - Relatou que se o DEA não indicar choque, deverá reiniciar a RCP, } \\
\text { caso a vítima não retome a consciência. }\end{array}$ & $1,41 \pm 1,35$ & $1,92 \pm 1,18$ & $0,046^{*}$ \\
\hline $\begin{array}{l}15 \text { - Relatou que mesmo se a vítima retomar a consciência, o aparelho } \\
\text { não deve ser desligado e as pás não devem ser removidas ou } \\
\text { desconectadas até que o SME assume o caso. }\end{array}$ & $0,82 \pm 0,74$ & $1,68 \pm 1,15$ & $<0,001^{*}$ \\
\hline $\begin{array}{l}16 \text { - Relatou que se não houver suspeita de trauma e a vítima já } \\
\text { apresentar respiração normal e pulso, o socorrista poderá colocá-la em } \\
\text { posição de recuperação, porém deverá permanecer no local até que o } \\
\text { SME chegue. }\end{array}$ & $1,70 \pm 1,34$ & $2,27 \pm 1,13$ & $0,022^{*}$ \\
\hline $\begin{array}{l}17 \text { - Relatou que se houver excesso de pelos no tórax, deverá remover } \\
\text { o excesso. }\end{array}$ & $0,88 \pm 0,93$ & $1,98 \pm 1,15$ & $<0,001^{*}$ \\
\hline 18 - Relatou que se o tórax estiver molhado, deverá secar por completo & $1,90 \pm 1,23$ & $2,31 \pm 1,06$ & 0,074 \\
\hline
\end{tabular}


Comparando a média do escore na avaliação prática, observou-se que a intervenção educativa, influenciou de forma significativa na média de acerto de todas as etapas dos procedimentos de emergência, com exceção ao item "Encaixou o conector das pás (eletrodos) ao aparelho" $(p=0,359)$ e "Relatou que se o tórax estiver molhado, deverá secar por completo" $(\mathrm{p}=0,074)$. A Tabela 2 apresenta a distribuição da média das execuções corretas na avaliação prática dos estudantes.

Por meio dos resultados apresentados, pode-se observar que os estudantes assimilaram mais o conhecimento prático do que teórico.

\section{Limitação do estudo}

Não foi possível concluir se há diferenças entre o nível de conhecimento de estudantes de escolas públicas e particulares. Porém, é passível de questionamento se os estudantes manteriam o nível de conhecimento apresentado em um período de tempo mais prolongado, uma vez que o intervalo de quinze dias entre uma intervenção e outra é relativamente curto.

\section{DISCUSSÃO}

A literatura é escassa de publicações sobre a PCR pré-hospitalar, muito menos sobre a instrução em estudantes cursando as series escolares básicas. Tal assunto é de importante relevância a sociedade, pois a utilização de técnicas de RCP em um indivíduo em PCR de modo precoce, melhora os índices de morbidade e mortalidade. Mesmo assim, ainda há intensa dificuldade a repassar tal saber a população (MORAIS DA, CARVALHO DV, CORREA AdR, 2014; CARDOSO RR et al., 2017).

Em virtude dessa lacuna de conhecimento apresentada pela população geral, as escolas são um dos melhores locais para abordar tal temática, logo que são instituições nas quais muitas vezes se encontra um rol relativamente expressivo de indivíduos, funcionando assim como um perfeito laboratório, para repassar saberes e testar o nível de conhecimento dos participantes (FERNANDES JMG et al., 2014)

A educação em saúde deve ser realizada de uma maneira que instigue um pensamento crítico e reflexivo, a fim de influenciar o sujeito a produzir ações transformadoras na sociedade. Isto é, tornar-se um indivíduo atuante quanto a ações que proporcione bem-estar ao seu redor, de maneira ativa. No tocante a PCR, executar a RCP de maneira eficiente, até a chegada de uma equipe médica, assim contribuindo de maneira decisiva no prognóstico do paciente (GUIMARAES EA et al., 2016; FALKENBERG MB et al., 2014).

Por meio do diálogo com os adolescentes participantes do estudo, foram notados seus conhecimentos a respeito da relevância do aparelho cardiovascular e dos sinais vitais. Utilizaram tanto termos científicos como populares, para referir de maneira leiga ao assunto abordado. Todavia, foi estabelecido de maneira unânime que tal sistema orgânico é fundamental para a vida.

Frente o exposto, percebe-se a importância da atuação de profissionais da saúde na formação acadêmica e social de indivíduos os quais cursam séries educacionais básicas. Sendo que, uma maneira de produzir bons resultados é aquela na qual são utilizadas técnicas de aprendizado ativo. Além disso, faz-se importante a capacitação de pessoas leigas quanto a RCP, com intenção de produzir atendimentos mais rápidos e frutíferos a vítimas de PCR, acontecimento o qual possui alta incidência, mortalidade e morbidade.

\section{CONCLUSÃO}

A partir dos resultados presentes, pode-se sugerir que a intervenção educativa sobre RCP proposta é efetiva e conveniente para o aprendizado teórico e prático. São necessárias mais publicações a respeito desta temática, com o propósito de aperfeiçoamento da maneira como tal ensinamento deve ser realizado a crianças e adolescente. Considera-se que mais estudos sobre o tema abordado devam ser realizados, para que uma grande quantidade de pessoas possa estar qualificada para tais situações, levando à uma maior relevância para a comunidade científica. 


\section{REFERÊNCIAS}

1. CARDOSO RR, SOARES LGB, CALIXTO FRP, et al. Suporte Básico de Vida para leigos: uma revisão integrativa. Unimontes Científica. 2017 jul./dez.; 19(2).

2. FALKENBERG MB, MENDES TDPL, MORAES EPD, et al. Educação em saúde e educação na saúde: conceitos e implicações para a saúde coletiva. Ciênc. saúde coletiva. 2014 mar; 19(3).

3. FERNANDES JMG, LEITE ALDS, AUTO BDSD, et al. Ensino de Suporte Básico de Vida para Alunos de Escolas Pública e Privada do Ensino Médio. Arq Bras Cardiol. 2014.

4. GUIMARAES EA, SANTOS ADN, REIS CO, et al. Parada Cardiorrespiratória: respostas emergenciais no treinamento desportivo. Ciafis. 2016 set.

5. HASSELQVIST-AX I, RIVA G, HERLITZ J, et al. Early Cardiopulmonary Resuscitation in Out-of-Hospital Cardiac Arrest. N Engl J Med. junho 2015; 372(24).

6. MORAIS DA, CARVALHO DV, CORREA AR. Parada cardíaca extra-hospitalar: fatores determinantes da sobrevida imediata após manobras de ressuscitação cardiopulmonar.Rev. Latino-Am. Enfermagem. 2014 jul-agost; 22(4).

7. MOTA LL. Instrumento educativo para escolares sobre temas de atenção às urgências na perspectiva dos profissionais do serviço de atendimento móvel de urgência. Universidade Federal de Santa Catarina. Rev Esc Enferm USP. 2013.

8. TAVARES A, PEDRO N, URBANO J. Ausência de formação em suporte básico de vida pelo cidadão: um problema de saúde pública? Qual a idade certa para iniciar?. Revista Portuguesa de Saúde Pública, v. 34, n. 1, p. 101-104, 2016. 